\title{
Ventricular Involvement Only
}

National Cancer Institute

\section{Source}

National Cancer Institute. Ventricular Involvement Only. NCI Thesaurus. Code C131618.

A finding indicating that a neoplasm affects exclusively a brain ventricle. 